\title{
Laser Brazing of Diamond Grits Using a Cu-15Ti-10Sn Brazing Alloy
}

\author{
Sheng-Fang Huang, Hsien-Lung Tsai and Shun-Tian Lin \\ Department of Mechanical Engineering National Taiwan University of Science and Technology Taipei 106, Taiwan, R.O. China
}

Brazing of diamond grits onto a steel substrate, using a Cu-Ti-Sn brazing alloy, was carried out via laser brazing in an argon atmosphere. The laser power was maintained at either 400,450 , or $500 \mathrm{~W}$, while the laser irradiation time was 10 seconds. For a brazed layer of about 7 mm in diameter and $90 \mu \mathrm{m}$ in thickness, a power input of $450 \mathrm{~W}$ was found to yield the optimal result. Due to the short irradiation time at high temperatures, discrete TiC grains of about $100 \mathrm{~nm}$ in size developed, instead of a continuous TiC layer formed at higher and longer process conditions, on the diamond surface. These TiC grains still effectively reduced the stress associated with the mismatch between the diamond grit and $\mathrm{Cu}$ in the aspects of lattice constant and thermal expansion coefficient. Accordingly, only a low percentage (about 5\%) of diamond grits was pulled out of the brazed layer after a grinding test.

(Received April 3, 2002; Accepted August 27, 2002)

Keywords: laser brazing, diamond tool, copper alloy, active brazing

\section{Introduction}

Diamond tools are ideal for the machining of hard materials, due to their extreme high hardness. Diamond tools are usually prepared in the form of composite structures, wherein diamond grits are bonded using either a plastic, ceramic, or metallic bonding matrix. Among these three categories of bonding agents, metallic bonding agents offer optimal mechanical and thermal properties and are the optimal bonding materials in the fabrication of diamond tools. ${ }^{1-4)}$ One important category of diamond tools is diamond tools having only monolayer of diamond grits, which are usually fabricated by electroplating or vacuum brazing. ${ }^{5,6)}$ Thus, depending on the fabrication method, the holding of the diamond grit by the metal matrix can be mechanical, chemical or a combination of both. ${ }^{1,2)}$ As the interface between the diamond grit and metal matrix during utilization withstands the moment to which the diamond grit is subjected, a strong interfacial cohesion arising from an interfacial reaction is the basic requirement for enhancing tool life. Electroplated diamond tools involve weak interfacial cohesion strength between the diamond grit and metal matrix. Pull-out of diamond grits usually predominates as a cause for tool failure. On the other hand, diamond tools fabricated by vacuum brazing usually exhibit enhanced performance compared with the plated tools, due to the fact that the interfacial bonding strength between the diamond grit and the bonding matrix is usually a chemical one.

Chemical bonding between the diamond grit and metal matrix can develop with the addition of an active element in the alloy system. ${ }^{7-13)}$ For example, the wetting and bonding of a copper-tin alloy to diamond is poor, but can be dramatically improved by the addition of a low concentration of an active element, such as chromium, titanium, or vanadium. ${ }^{7-10)}$ Another example is that the fracture toughness of a composite structure composed of $\mathrm{Cu}-10 \% \mathrm{Ni}$ alloy reinforced with diamond grits was significantly improved when the diamond grits were coated with a thin titanium layer. ${ }^{11)}$ These active elements can form transitional carbide layers between the diamond grit and the metal matrix. The carbide layer behaves as a diffusing barrier to avoid excessive reaction of the matrix with the diamond grit, and as a buffer zone to reduce the stress associated with the differences in lattice constants and thermal expansion coefficients between the diamond grit and the bonding matrix. For example, when $\mathrm{Cu}-$ 15Ti-10Sn alloy was used as the brazing alloy, the intermediate TiC layer ideally alleviated the mismatch between the diamond crystal and the bonding matrix. The interface between the diamond crystal and the TiC crystal was a semicoherent one. The interfacial stress could be relieved by a registry of six times the interplanar spacing of diamond (111) planes $(6 \times 0.206 \mathrm{~nm}=1.236 \mathrm{~nm})$ to five times the TiC $(111)$ planes $(5 \times 0.25 \mathrm{~nm}=1.250 \mathrm{~nm})$ (six-to-five registry) in a short range and further by the grain boundaries in a longer range. ${ }^{12)}$ Near the matrix side, a segregated layer of Sn-Ti intermetallic compounds was found, which also exhibited a semi-coherent interface with the metal matrix. ${ }^{13)}$

With all the above-mentioned attributes, diamond tools fabricated by vacuum brazing still possess a vital limitation. No plastically deformed substrate should be used as high temperature brazing practice can cause shape distortion of the substrate. For substrates inheriting residual stress from prior processing, only an electroplating process can be employed to fabricate diamond tools. An alternative to solve such a problem is to apply heat to activate the brazing process in a narrowly selected area, and carry out the brazing process continuously to fully heat the whole brazed area. Laser beams have the properties to function in such an application, such as high energy density, low energy input, and small beam diameter. These attributes can achieve the goals of short heat treatment duration, small heat affected zone, and, consequently, minimal deformation of the substrate. In addition, a standard laser processing equipment is commercially available, so that it is easy to control the process sequence. It is thus the goal of this study to evaluate the feasibility of the laser processing in the fabrication of brazed diamond tools.

\section{Experimental Procedures}

The brazing alloy was a $\mathrm{Cu}-10 \mathrm{Sn}-15 \mathrm{Ti}$ (mass\%) powder, prepared via gas atomization. It had a mean particle size of 
$24 \mu \mathrm{m}$ and a solidus temperature of $880^{\circ} \mathrm{C}$. The particle size distribution showed a bimodal mode, with the larger particles $(>50 \mu \mathrm{m})$ being rich in $\mathrm{Cu}$ and the smaller ones $(<10 \mu \mathrm{m})$ being rich in Sn and Ti. Synthetic diamond grits (GE. 61203, Fine 300) having particle sizes ranging from 20 to $30 \mu \mathrm{m}$ were first mixed with the brazing powder in a volumetric ratio of 10 to 90 and applied onto a steel substrate (AISI 1045) having a thickness of $1.5 \mathrm{~mm}$. Laser brazing was carried out using a $\mathrm{CO}_{2}$ laser (Rofin-Sinar 820). The arrangement of the equipment and the sample during laser brazing is illustrated in Fig. 1. The laser beam was originally a TEM 00 (Transverse Electro-Magnetic) mode and it had a beam diameter of about $19 \mathrm{~mm}$. After passing through the beam regularizer, which was composed of four pieces of copper mirrors, the beam was narrowed down to a diameter of $10 \mathrm{~mm}$. Three different levels of power input were applied, 400, 450, and $500 \mathrm{~W}$. The irradiation time of each practice was 10 seconds. Argon gas, having a flow rate of $100 \mathrm{~cm}^{3} / \mathrm{s}$, was used as a shielding gas to protect the diamond grits and brazing alloy from oxidation. A data acquisition system attached with a K type thermocouple, which was inserted into the substrate and maintained a distance of $0.02 \mathrm{~mm}$ away from the interface between the brazing alloy and the substrate, was used to measure the temperature profile during brazing practice.

Phase analysis of the brazing alloy prior to and subsequent to the brazing practice was carried out using an X-ray diffractometer (Rigaku D/Max RC). The brazed structure was observed using a diamond grinding wheel in cross sections that were either parallel to or perpendicular to the interface between the brazing alloy and the substrate. An optical microscope was used to examine the structure and electron probe microanalysis (EPMA, JEOL JXA-8600SX) was used to analyze the distribution of elements in the brazed layer. The structure of the interface between the diamond grit and the brazing alloy was studied by electrolyzing the metal matrix from the specimen at $20 \mathrm{~V}$ in a diluted sulfuric acid (20 vol\%), which removed the brazing alloy from the brazed layer and left behind diamond grits. The microstructure of the surface of diamond grits was examined using a field emission scanning electron microscope (FESEM, LEO 1530), with an energy dispersive X-ray analyzer (EDS). An abrasion test was carried out in a pin-on-disk manner, where the diamond tool was the pin and a granite plate $(\mathrm{Hv}=9 \mathrm{GPa})$ was the disk.

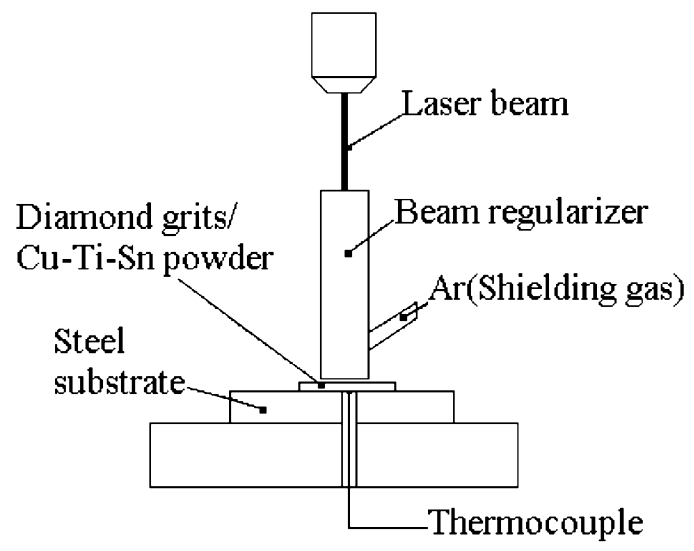

Fig. 1 Experimental setup for laser brazing.
The diamond tool had a brazed layer of $2 \mathrm{~mm}$ in width and $5 \mathrm{~mm}$ in length. It rotated on the granite plate along a circle of $50 \mathrm{~mm}$ in diameter, with its length direction perpendicular to the radial direction of the circle. The relative velocity of pin to disk was $0.67 \mathrm{~m} / \mathrm{s}$, and the load during the test was 29.4 N. After a traverse distance of $1000 \mathrm{~m}$, the microstructure of the abraded layer of the diamond tool was examined using an SEM (Cambridge S360).

\section{Results and Discussion}

Figure 2 shows the temperature profiles measured at $0.02 \mathrm{~mm}$ below the interface between the brazed layer and the substrate. For a power input of $400 \mathrm{~W}$, the temperature reached a level of about $900^{\circ} \mathrm{C}$ in about $3.5 \mathrm{~s}$ and maintained this temperature until the power input was shut down. For a power input of $450 \mathrm{~W}$, the temperature reached a level of about $900^{\circ} \mathrm{C}$ in about $2.5 \mathrm{~s}$ and kept rising up to the maximum of $980^{\circ} \mathrm{C}$. For a power input of $500 \mathrm{~W}$, the temperature rapidly reached $930^{\circ} \mathrm{C}$ in about $1.8 \mathrm{~s}$ and kept rising up to the maximum of $1050^{\circ} \mathrm{C}$. When the power was shut down, the temperature dropped to about $200^{\circ} \mathrm{C}$ in $20 \mathrm{~s}$. The cooling rate at high temperatures was about $67^{\circ} \mathrm{C} / \mathrm{s}$ or $4000^{\circ} \mathrm{C} / \mathrm{min}$. It is noted that the solidus temperature of this brazing alloy was about $880^{\circ} \mathrm{C}$. Accordingly, the change in the slope of temperature rise from a steep rise to a gradual rise was thus due to the fact that the brazing alloy reached a state of coexistence of solid and liquid phases. Different dimensions of heat-affected zones in the steel substrate were expected for different power inputs. Figure 3 shows the morphologies of three specimens that were exposed to different power inputs. Because the substrates were $1.5 \mathrm{~mm}$ in thickness, the real depths of the heataffected zones could not be determined, and only their widths were measured. Though the laser beam was narrowed down to a diameter of $10 \mathrm{~mm}$, the widths of the heat-affect zones for power inputs of 400, 450, and $500 \mathrm{~W}$ were about 6.8, 7.5, and $8.5 \mathrm{~mm}$, respectively.

Figure 4 shows the X-ray diffraction (XRD) patterns of the as-received powder and the brazed layer exposed to a laser power of $450 \mathrm{~W}$ for $10 \mathrm{~s}$. The as-received powder was primarily composed of three different phases, i.e., Cu based solid solution, Ti, and $\mathrm{Sn}_{3} \mathrm{Ti}_{5}$. Subsequent to the laser brazing practice, the brazed layer was composed of several $\mathrm{Sn}-\mathrm{Ti}, \mathrm{Cu}-\mathrm{Ti}$, and $\mathrm{Cu}-\mathrm{Sn}$ intermetallic compounds, in addition to the princi-

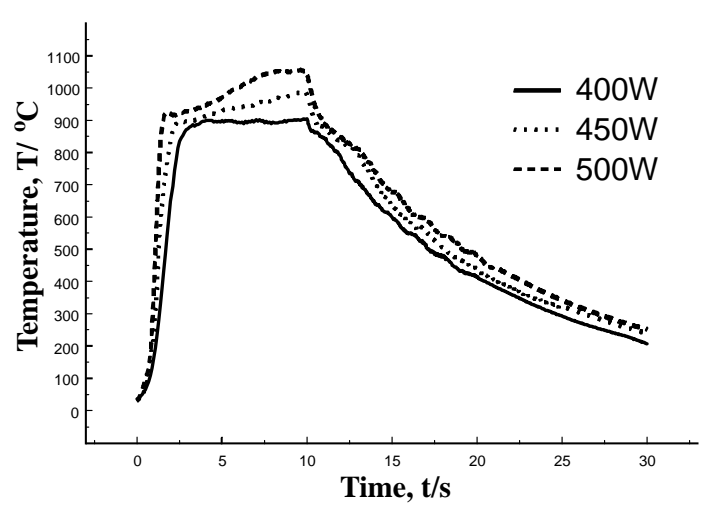

Fig. 2 Temperature profiles at the interface between the brazed layer and the steel substrate for different power inputs in laser brazing. 

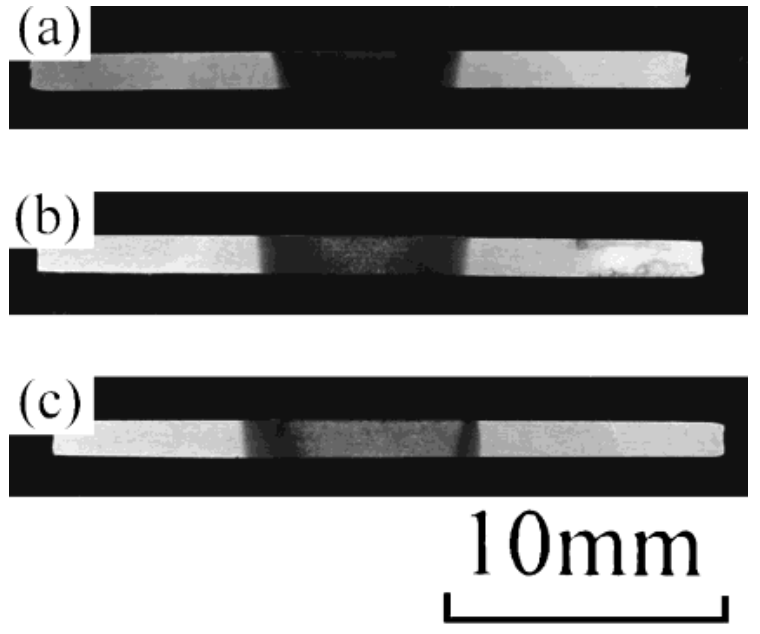

Fig. 3 A comparison of the heat-affected zones in the steel substrate for three specimens prepared with different power inputs. $400 \mathrm{~W}$ (a), $450 \mathrm{~W}$ (b), $500 \mathrm{~W}(\mathrm{c})$.

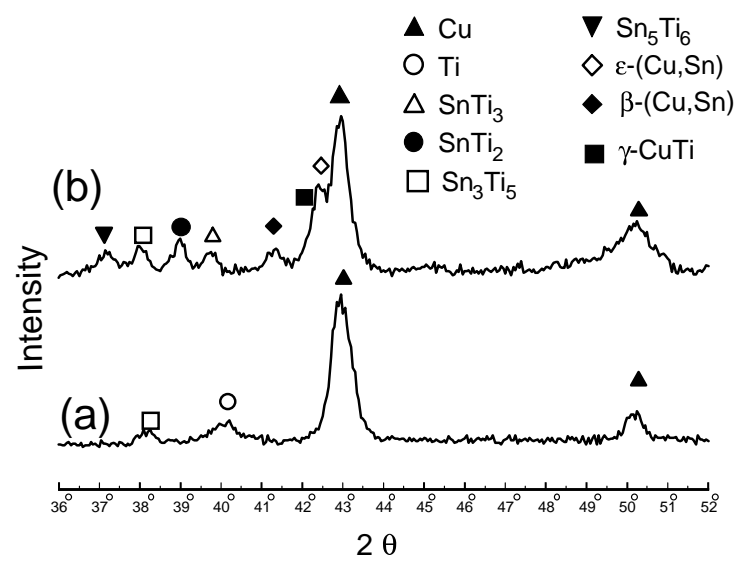

Fig. 4 XRD patterns of the as-received powder (a) and the brazed layer processed at a laser power of $450 \mathrm{~W}$ for $10 \mathrm{~s}$ (b).

pal Cu-based solid solution. These intermetallic compounds included $\mathrm{Sn}_{5} \mathrm{Ti}_{6}, \mathrm{Sn}_{3} \mathrm{Ti}_{5}, \mathrm{SnTi}_{2}, \mathrm{SnTi}_{3}, \gamma-\mathrm{CuTi}, \varepsilon-(\mathrm{Cu}, \mathrm{Sn})$, and $\beta-(\mathrm{Cu}, \mathrm{Sn})$. The XRD patterns of the laser-brazed samples with different power inputs were almost the same, and were similar to vacuum-brazed ones, ${ }^{12)}$ whereas had slightly different relative intensity of each compound. Due to the existence of these intermetallic compounds, the hardness of the brazed layer lay between 3.2 and 3.5 GPa.

Figure 5 shows optical micrographs of the brazed layers of the specimens exposed to different laser power inputs. These surfaces were prepared approximately parallel to the interfaces between the brazing alloy and the substrate. For a power input of $400 \mathrm{~W}$, there are abundant large pores in the brazed layer, due to insufficient melting of the brazing alloy. The adhesion of the brazed layer to the substrate was very weak, and hence the brazed layer could be easily peeled off during grinding. For a power input of $500 \mathrm{~W}$, pores are hardly found in the brazed layer, but clustering of diamond grits is observed in the brazed layer. As indicated previously, brazing was carried out in a domain where both the solid and liquid phases coexisted. A high power input caused the formation of a large fraction of liquid phase in the brazed layer, which could effectively exert surface tension on the diamond grits. Accord-
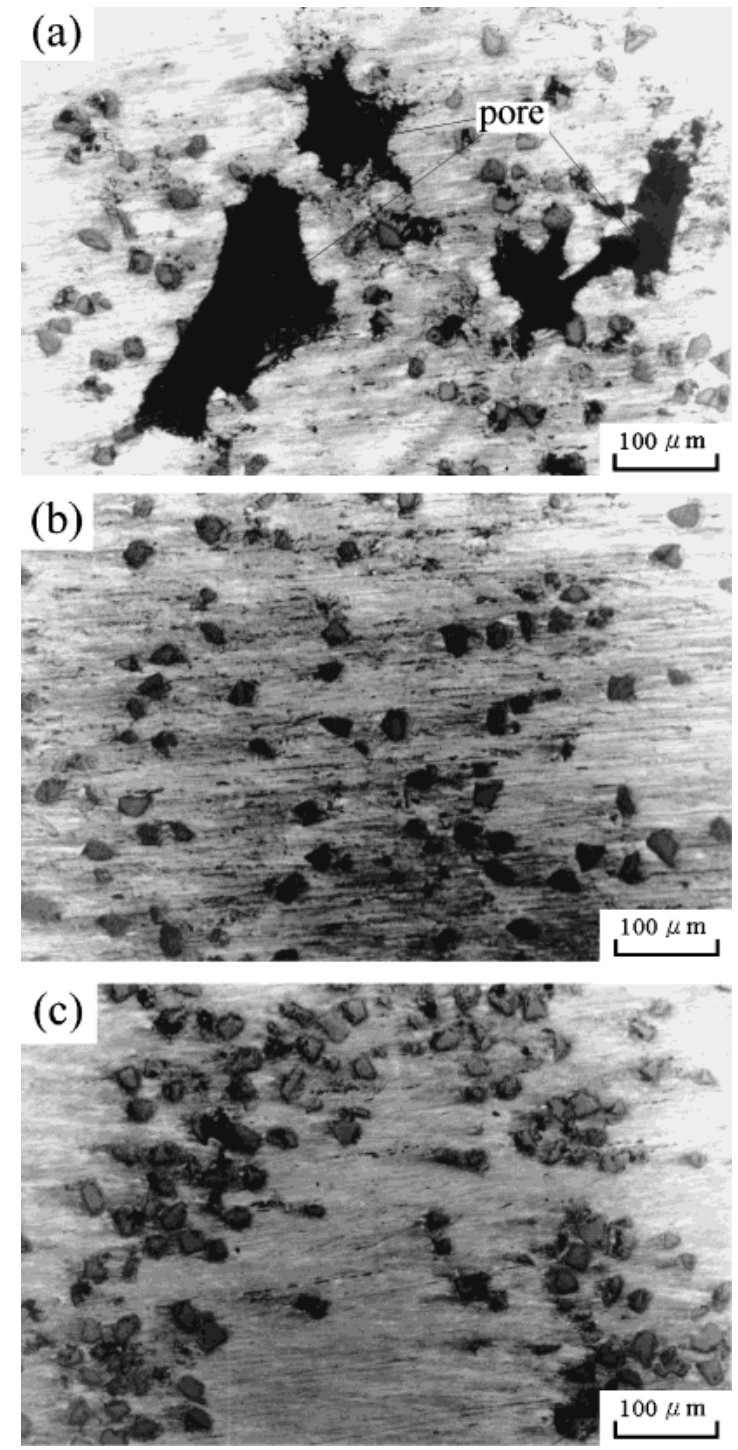

Fig. 5 Optical micrographs of the brazed layers that were parallel to the interfaces between the brazed layer and the substrate. $400 \mathrm{~W}$ (a), $450 \mathrm{~W}$ (b), $500 \mathrm{~W}$ (c).

ingly, due to the fact that diamond has a much lower density than the liquid metal phase, these diamond grits tend to cluster together when the relative fraction of the liquid phase in the brazing alloy is too high. The optimal power input in this study is $450 \mathrm{~W}$, because pores are hardly observed in the brazed layer and the distribution of diamond grits is very uniform. A similar phenomenon could also be observed in the optical micrographs of the brazed layers that were prepared cross-sectionally across the interface between the brazing alloy and the substrate, which are shown in Fig. 6. The diamond grits near the surface of the brazed layer for a power input of $500 \mathrm{~W}$ were easily pulled out from the brazed layer, as shown in Fig. 6. This phenomenon might have arisen from the degradation of diamond grits at high temperatures. In fact, synthetic diamond grits can degrade very fast, by transforming into graphite, ${ }^{14)}$ when exposed to high temperatures. On the other hand, for a power input of $450 \mathrm{~W}$, a flat brazed layer with diamond grits strongly bonded to the brazing alloy could be achieved. Such a power input is thus believed to be the optimal one. 

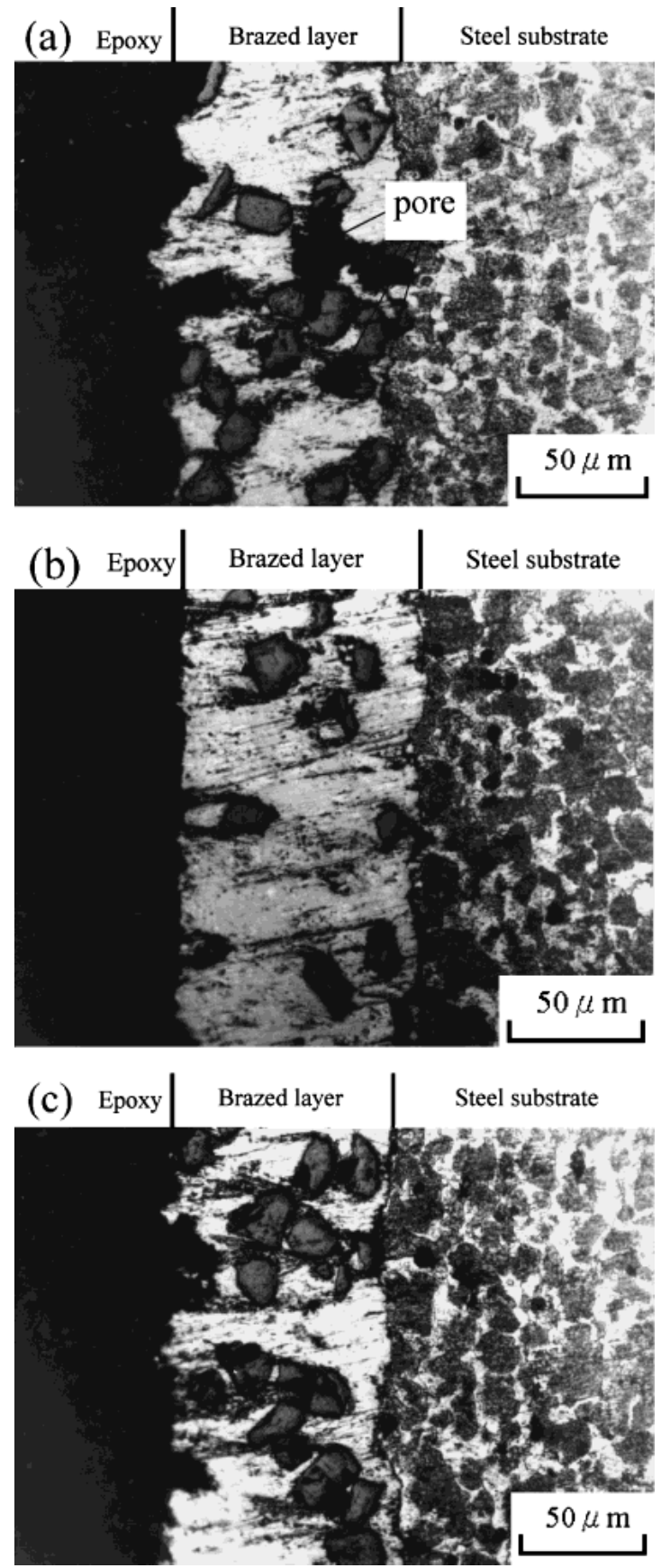

Fig. 6 Optical micrographs of the brazed layers that were perpendicular to the interface between the brazed layer and the interface. $400 \mathrm{~W}$ (a), $450 \mathrm{~W}$ (b), $500 \mathrm{~W}(\mathrm{c})$.

Figure 7 shows the surface of a diamond grit for the specimen laser-brazed at a power input of $450 \mathrm{~W}$, whose brazed alloy was etched away by electrolyzing the metal matrix from the specimen at $20 \mathrm{~V}$ in a diluted sulfuric acid (20 vol\%). There are abundant small discrete grains formed on the surface of the diamond grit, with their mean grain size lying in the range near $100 \mathrm{~nm}$. Previous studies indicated that a continuous TiC layer could form on the surface of diamond when $\mathrm{Cu}$-based alloys containing low concentrations of $\mathrm{Ti}$ were used as the brazing alloys. ${ }^{7)}$ The thickness of the TiC layer could reach about $500 \mathrm{~nm}$ when the specimen was processed at $925^{\circ} \mathrm{C}$ for 5 minutes ${ }^{12,13)}$ or about $4 \mu \mathrm{m}$ for a specimen processed at $900^{\circ} \mathrm{C}$ for 1 h. ${ }^{9)}$ Thus, based on EDS result,

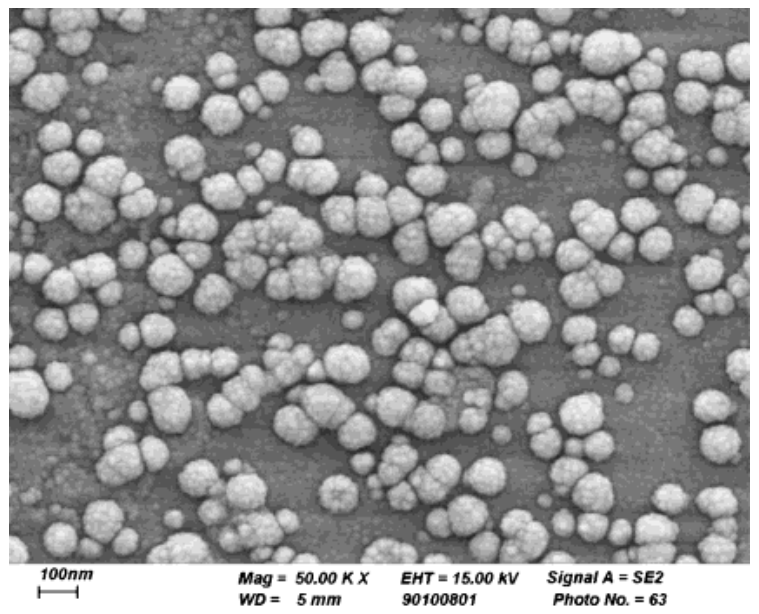

Fig. 7 Micrograph of discrete TiC grains on the surface of a diamond grit for the specimen processed at a power input of $450 \mathrm{~W}$. The brazed layer was leached out of the structure by electrolyzing the metal matrix from the specimen at $20 \mathrm{~V}$ in a diluted sulfuric acid (20 vol\%).

the discrete grains observed in this study were mainly composed of $\mathrm{Ti}$ and $\mathrm{C}$. They are believed to be grains of $\mathrm{TiC}$. The discrete $\mathrm{TiC}$ grains were attributed to the short process time, and could be deemed as a state lying close to the nucleation stage for the growth of a continuous TiC layer. Due to the chemical inertness of diamond, it is difficult to strongly bond diamond grits to the matrix without a chemical reaction occurring in the adjoining interface. Indeed, the interfacial microstructure, mainly related to the constrained lattices between dissimilar adjacent crystals, and the stress-relief mechanism of the constrained lattices have a significant effect on the bonding strength between the diamond grit and the brazing alloy. ${ }^{12)}$ It was previously shown that the lattice mismatch between the TiC crystal and the diamond grit could be effectively relieved by a registry of six times the interplanar spacing of diamond $(111)$ planes $(6 \times 0.206 \mathrm{~nm}=1.236 \mathrm{~nm})$ to five times the $\mathrm{TiC}(111)$ planes $(5 \times 0.25 \mathrm{~nm}=1.250 \mathrm{~nm})$ (six-to-five registry) in a shorter range, and by the abundant existence of $\mathrm{TiC}$ grain boundaries (grain size $=40-50 \mathrm{~nm}$ ) in a longer range. ${ }^{12)}$ Thus, the existence of the interfacial TiC crystals in the form of discrete grains instead of a continuous layer could be effective in improving the interfacial bonding strength between the diamond grit and the brazing alloy.

Figure 8 shows the dot mappings of elements near the interface between the diamond grit and the brazing alloy, for the specimen exposed to a power input of $450 \mathrm{~W}$. Due to the fact that several different intermetallic compounds existed in the brazed layer, the distribution of the elements was not uniform. The XRD results indicate that the Sn-Ti based intermetallic compounds are the principal dispersed phases in the $\mathrm{Cu}$-based matrix. The interface between the diamond grit and the brazed alloy is rich in $\mathrm{Ti}$, but it does not resemble a continuous $\mathrm{Sn}-\mathrm{Ti}$ intermetallic compound layer observed in a vacuum-brazed specimen. ${ }^{12)}$ Such a difference was due to the fact that the growth pattern of the $\mathrm{Sn}-\mathrm{Ti}$ intermetallic compound layer is a diffusion-controlled process. The diffusion time for the laser-processed specimen was too short to induce the formation of the continuous $\mathrm{Sn}-\mathrm{Ti}$ intermetallic compound layer. In this study, moving in the direction from the diamond grit to the brazing alloy, the small TiC crystals 


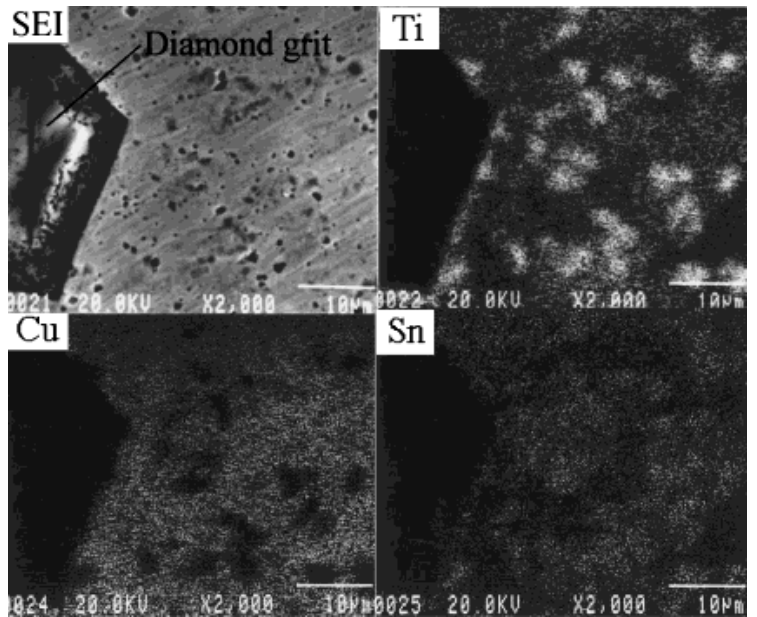

Fig. 8 Secondary electron image and dot mappings of $\mathrm{Ti}, \mathrm{Cu}$, and $\mathrm{Sn}$ near the interface between a diamond grit and the brazing alloy for the specimen processed at a power input of $450 \mathrm{~W}$.

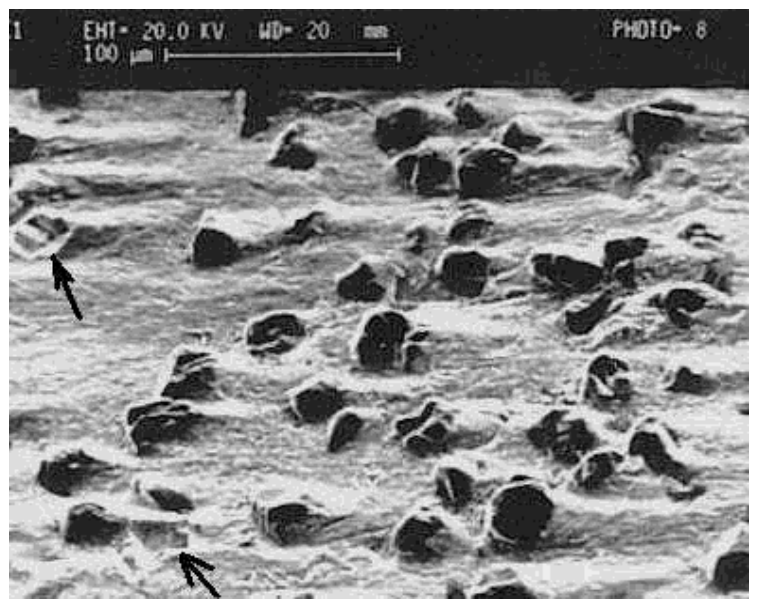

Fig. 9 Morphology of the brazed layer after the pin-on-disk abrasion test. A low percentage (about $5 \%$ ) of diamond grits were pulled out of the brazed layer after the test, which are indicated by the arrows.

and, subsequently, the Sn-Ti intermetallic compounds gradually relieved the stresses arising from the mismatch in lattice constants and difference in thermal expansion coefficients between diamonds and the $\mathrm{Cu}$-based alloy. ${ }^{13)}$

Figure 9 shows the morphology of the brazed layer after the pin-on-disk abrasion test. Most of the diamond grits were retained in the brazed layer after the test, with about $5 \%$ of them being pulled out of the brazed layer. Though the pull-out percentage of diamond grits was much better than those achieved in most electroplated tools, it was still slightly worse than those achieved in vacuum-brazed tools. Accordingly, it is believed that the formation of the continuous TiC layer and the continuous Sn-Ti intermetallic compound layer near the interface between the diamond grit and the brazed layer should further improve their bonding strength. This goal could be achieved by increasing the irradiation time of the laser braz- ing process.

\section{Conclusion}

Brazing of diamond grits onto a selected area of a steel substrate was carried out via laser brazing, using a $\mathrm{Cu}-\mathrm{Ti}-\mathrm{Sn}$ alloy. For an effective area $7 \mathrm{~mm}$ in diameter and $90 \mu \mathrm{m}$ in depth, a laser power input of $450 \mathrm{~W}$ and an irradiation time of $10 \mathrm{~s}$ were found to be capable of successfully brazing the diamond grits onto the steel substrate. Several intermetallic compounds of $\mathrm{Sn}-\mathrm{Ti}, \mathrm{Cu}-\mathrm{Ti}$, and $\mathrm{Cu}-\mathrm{Sn}$, including $\mathrm{Sn}_{5} \mathrm{Ti}_{6}$, $\mathrm{Sn}_{3} \mathrm{Ti}_{5}, \mathrm{SnTi}_{2}, \mathrm{SnTi}_{3}, \gamma-\mathrm{CuTi}, \varepsilon-(\mathrm{Cu}, \mathrm{Sn})$, and $\beta-(\mathrm{Cu}, \mathrm{Sn})$, developed after the brazing process. There developed a discontinuous layer of discrete $\mathrm{TiC}$ grains having a mean grain size of about $100 \mathrm{~nm}$ on the diamond surface. On top of that, formation of $\mathrm{Sn}-\mathrm{Ti}$ intermetallic compound layer seemed visible yet insignificant, due to the short irradiation time at high temperatures. Though such a transition in structure from the diamond grit to the brazing alloy did not cover all the interfacial area between the diamond grit and the brazing alloy, it was still effective in reducing the interfacial stress between the diamond grit and the brazing alloy. Based on a pin-ondisk test against a granite substrate of high hardness, only a low percentage (about 5\%) of diamond grits was pull-out of the brazed layer after test.

\section{Acknowledgement}

This research was financially supported by the National Science Council, Taiwan, R.O.C. (NSC 90-2216-E-011-046). Assistance from Mr. W. C. Li is greatly appreciated.

\section{REFERENCES}

1) J. Konstanty: Ind. Dia. Rev. 51 (1991) 27-31.

2) T. Fujimori, Y. Yamamoto and A. Okada: J. Mater. Sci. Soc. Jap. 32 (1995) 39-49.

3) M. Igharo and J. Russel: Surf. Eng. 10(1) (1994) 52-55.

4) T. Yamazaki and A. Suzumuza: J. Mater. Sci. (1998) 1379-1384.

5) H. K. Tönshoff and C. Marzenell: Industrial Diamond Review 59 (583) (1999) 309-315.

6) S. M. Chen and S. T. Lin: J. Mater. Eng. Per. 5 (1996) 761-766.

7) M. Scott, M. Nicholas and B. Dewar: J. Mater. Sci. 10 (1975) 1833 1840.

8) R. Standing and M. Nicholas: J. Mater. Sci. 13 (1978) 1509-1514.

9) Z. Lin and R. A. Queeney: Modern Developments in Powder Metallurgy, compiled By P. U. Gummeson etc. (Metal Powder Industrial Federation, Princeton, N.J) 20 (1988) 443-450.

10) Y. Z. Hsieh, J. F. Chen and S. T. Lin: J. Mater. Sci. 35 (2000) $5383-$ 5387.

11) Z. Lin and R. A. Queeney: Powder Metall. Inter. 18(2) (1986) 76-78.

12) W. C. Li, C. Liang and S. T. Lin: Diamond and Related Materials, 11 (2002) 1366-1373.

13) W. C. Li, C. Liang and S. T. Lin: Metall. Mater. Trans. (A) 33A (2002) 2163-2172.

14) General Electric Brochure, Superabrasive Products for Grinding Wheels, Saw Blades, Electroplated Tools, Polishing Compounds, and Drill Bits, SMD 44-493, Worthington, OH, p. 16. 